\title{
Critic and Maut Methods for the Contract Manufacturer Selection Problem
}

\author{
Esra Aytaç Adalı
}

Department of Business Administration, Pamukkale University, Ayşegül Tuş Işık

Department of Business Administration, Pamukkale University, Denizli, Turkey,

\begin{abstract}
Nowadays companies should respond and satisfy the customer needs effectively and quickly to establish a position in the competitive market. One of the ways of achieving these goals is the outsourcing their some manufacturing operations to contract manufacturers. Outsourcing manufacturing operation to contract manufacturers decreases the operational cost, increases the profit and provides the flexibility of production capability. So the selecting a contract manufacturer for a company is an important problem that must be dealt very carefully. This selection is influenced by quantitative and qualitative criteria and it is handled as Multi Criteria Decision Making (MCDM) problem. In this paper, CRITIC (CRiteria Importance Through Intercriteria Correlation) and MAUT (Multi Attribute Utility Theory) methods are applied to the contract manufacturer selection problem. The weights of the contract manufacturer selection criteria are derived from CRITIC method whereas the complete ranking of the contract manufacturer alternatives are obtained by using MAUT. Finally the results are discussed.
\end{abstract}

Keywords: MCDM, CRITIC, MAUT, contract manufacturer selection problem

\section{Introduction}

Today's business environment can be regarded as a variable and uncertain environment. Companies have to make a change in strategic view, applied tools and methods, shortened product life cycle due to numerous changes in business setting (Mohaghar et al., 2014).

Companies should adjust their manufacturing capacity effectively and quickly to respond and satisfy the customer needs. They can expand their manufacturing capacity by expanding existing plants, building new plants, automation and outsourcing production to contract manufacturers (Chen et al., 2005). Outsourcing is a business strategy which is a managed process of transferring operations to be performed by outside suppliers (Işıklar et al., 2007). In the past, outsourcing was primarily relegated to the procurement of non-core components and services. Today, the outsourcing trend has expanded to include core and non-core components, business processes, information technology processes, manufacturing and distribution activities and customer support activities (Hu and $\mathrm{Yu}, 2016$ ). In this manner outsourcing refers to a process in which a company lets a contract manufacturer manufacture parts and components, then assemble these parts and components and deliver the final product to customers (Chen et al., 2005). In this process selecting the proper contract manufacturer is the most important manufacturing decision to be made by the company. Because this decision directly affects the business success and competitive advantage. In the literature contract manufacturer selections at different industries are performed by different methods. Chen et al. (2005) computed process incapability index to determine the score index and used it to evaluate the process performance of contract manufacturers. Hu and Yu (2016) presented an integration of the voting method and the goal programming model for the electronic contract manufacturer selection problem.

In this study contract manufacturer selection problem is regarded as Multi Criteria Decision Making (MCDM) problem because of the multiple conflicting criteria in the decision process. So it presents the integration of two MCDM methods, CRITIC (CRiteria Importance Through Intercriteria Correlation) and MAUT (Multi Attribute Utility Theory). The main goal is 
to assist efficiently the decision makers in determining the most appropriate contract manufacturer. Firstly, CRITIC is used to calculate the objective weights of each criterion related with contract manufacturer selection problem. CRITIC method considers the intensity of the contrast and the conflict of the decision making problem's structure (Diakoulaki et al., 1995). These contrasts between criteria are determined by correlation analysis (Yılmaz and Harmancıoğlu, 2010). Finally, MAUT is employed to present a ranking of potential contract manufacturers. MAUT allows using an appropriate multiple-objective utility function for identifying trade-offs and comparing the various objectives in a consistent manner (Kailiponi, 2010). MAUT attaches a utility value to each alternative and ranks the alternatives by considering their utility namely contributions of each criterion (Gomez-Limon et al., 2003).

The rest of this paper is organized as follow. In the second section, a new decision making approach based on CRITIC and MAUT methods is introduced. In the third section, this approach is applied to the contract manufacturer selection problem of a textile company. In the last section the results of the application are presented and recommendations for the future studies are discussed.

\subsection{Critic Method}

CRITIC (CRiteria Importance Through Intercriteria Correlation) method is one of the weighting methods which determines objective weights for criteria. CRITIC method was proposed by Diakoulaki et al. in 1995. This method includes the intensity of the contrast and the conflict in the structure of the decision making problem (Diakoulaki et al., 1995). It uses correlation analysis to find out the contrasts between criteria (Yılmaz and Harmancioğlu, 2010). In this method the decision matrix is evaluated and the standard deviation of normalized criterion values by columns and the correlation coefficients of all pairs of columns are used to determine the criteria contrast (Madić and Radovanović, 2015).

In the literature there are many applications of CRITIC method. Diakoulaki et al. (1995) applied CRITIC method to a sample of Greek pharmaceutical industries evaluated with regard to three of the most prominent indices of a firm's performance. Yılmaz and Harmancıoğlu (2010) developed a water resource management model for the Gediz River Basin in Turkey. The management alternatives were evaluated with Simple Additive Weighting (SAW), Compromise Programming (CP) and Technique for Order Preference by Similarity to Ideal Solution (TOPSIS). During these evaluations entropy method, CRITIC method and the standard deviation method were used for objective criteria and Analytic Hierarchy Process (AHP) method was used for subjective criteria. Aznar Bellver et al. (2011) determined the value of a Spanish savings. During this valuation CRITIC method was used for finding the weight of variables and companies. Milic and Goran (2012) presented the algorithms of entropy, CRITIC and FANMA methods in detail. Then application of these methods was shown with an illustrative example and results namely the values of criteria weights were compared. Guo et al. (2013) aimed to construct an evaluation index system of city's soft power. For this aim they used AHP and CRITIC methods to determine index weight. Çakır and Perçin (2013) conducted the performance measurement of 10 logistics firms with three stage MCDM techniques. The weights of the criteria were determined with the CRITIC method at the first stage. Liu and Zhao (2013) proposed a dynamic comprehensive evaluation method with subjective and objective information. For this aim they used the combination of AHP and CRITIC methods to determine the index weight. Kazan and Ozdemir (2014) analyzed financial statements of the fourteen large-scale conglomerates which were traded on Istanbul Stock Exchange. Firstly nineteen financial ratios of these holdings and their financial ratio weights were calculated by CRITIC method and then financial performance scores were found by TOPSIS method. Alemiardakani (2014) used the entropy method, the Modified Digital Logic (MDL) method, CRITIC method, Numeric Logic, (NL) and Adjustable Mean Bars' (AMB). Then a combinative weighting scheme was proposed and used in the TOPSIS model. Iris (2014) generated a systematic approach to develop sustainability index for urban water management system in Macau. In this study a comparative analysis was conducted between CRITIC and AHP methods with the equal weighting method in evaluating urban water sustainability index. Kim and $\mathrm{Yu}(2015)$ proposed a real feature matching method. In this method the shape similarity between the candidate pairs in the two data sets through a linear sum of the weight was calculated computed using the CRITIC method. Madic and Radovanović (2015) handled the selection of the most appropriate Non-Traditional Machining Process (NTMP) for a given machining application. In this application the relative significance of criteria was determined with CRITIC method and considered complete ranking of competitive NTMPs are found with ROV method. Lu et al. (2015) used the combination of AHP and CRITIC methods to calculate the index evaluation system of educational information and determine the impact of the assessment indicators for education information development in Suzhou region.

The application steps of CRITIC method are presented in the following (Madić and Radovanović, 2015). Firstly it is assumed that there is a set of $m$ feasible alternatives $A_{i}(i=1,2, \ldots, m)$ and $n$ evaluation criteria $C_{j}(j=1,2, \ldots, n)$ in the problem. 
Step 1: The decision matrix $X$ is formed. It shows the performance of different alternatives with respect to various criteria.

$$
X=\left[x_{i j}\right]_{m \times n}=\left[\begin{array}{cccc}
x_{11} & x_{12} & \cdots & x_{1 n} \\
x_{21} & x_{22} & \cdots & x_{2 n} \\
\vdots & \vdots & \ddots & \vdots \\
x_{m 1} & x_{m 2} & \cdots & x_{m n}
\end{array}\right] \quad(i=1,2 \ldots, m \text { and } j=1,2, \ldots, n)
$$

$x_{i j}$ presents the performance value of ith alternative on $j$ th criterion.

Step 2: Decision matrix is normalized using the following equation:

$$
x_{i j}^{*}=\frac{x_{i j}-\min \left(x_{i j}\right)}{\max \left(x_{i j}\right)-\min \left(x_{i j}\right)} \quad i=1,2, \ldots, m \text { and } j=1,2, \ldots, n
$$

$\mathrm{X}_{\mathrm{ij}}^{*}$ is the normalized performance value of ith alternative on $j$ th criterion. Here it should be noted that normalization does not take into account the type of criteria.

Step 3: While determining the criteria weights, both standard deviation of the criterion and its correlation between other criteria are included. In this regard, the weight of the $j$ th criterion $\left(w_{j}\right)$ is obtained as:

$$
w_{j}=\frac{C_{j}}{\sum_{j=1}^{n} C_{j}}
$$

where $C_{j}$ is the quantity of information contained in jth criterion determined as:

$$
C_{j}=\sigma_{j} \sum_{j^{\prime}=1}^{n}\left(1-r_{j j^{\prime}}\right)
$$

where $\sigma_{j}$ is standard deviation of the jth criterion and $r_{j j}$ is the correlation coefficient between the two criteria. It can be concluded that this method gives the higher weight to the criterion which has high standard deviation and low correlation with other criteria (Aznar Bellver et al., 2011). Namely higher value of $C_{j}$ means that a greater amount of information is obtained from the given criterion so the relative significance of the criterion for the decision making problem is higher.

\subsection{MAUT (Multi Attribute Utility Theory)}

Multi Attribute Utility Theory (MAUT) methods are the parts of the Multi Attribute Decision Making methods (MADM). MAUT was largely developed by Keeney and Raiffa (1976) (Gomez-Limon et al., 2003). The underlying idea of MAUT is that in any decision problem there is a real valued function or utility which has to be maximized (Zietsman et al., 2006). Due to MAUT, the decision makers can compare all alternatives simultaneously (Wang et al., 2010). The decision maker's preferences are reflected in the form of the utility function which is defined over a set of criteria. Utility value derived from single attribute utility function is the performance of alternatives in MAUT (Pohekar and Ramachandran, 2004; Nikou, 2011). After computing the integrated utility of each alternative, the decision maker ranks the alternatives completely. Integrated utility functions can be either additively separable or multiplicatively separable with respect to single attribute utility (Pohekar and Ramachandran, 2004).

MAUT is a simple and intuitive approach for the decision makers. Moreover it allows the decision maker to allocate relative weights to the various criteria (Zietsman et al., 2006). So in the literature MAUT has been applied a wide range of decision making problems. Wang et al. (2002) presented a decision support system based on MAUT for dewatering systems selection. Seven main parameters were analyzed in the selection process. Loetscher and Keller (2002) 
developed a decision support system which was called SANEX. It operated in two steps. The second step was related with MAUT. In this step a model derived from MAUT used technical, socio-cultural and institutional criteria for decisions. Gomez-Limon et al. (2003) performed MAUT for computing relative and absolute risk aversion coefficients of farm systems. Ananda and Herath (2005) determined societal risk preferences on public forest land-use attributes using MAUT. Zietsman et al. (2006) performed MAUT for presenting decision making process concerning transportation programmes and projects in the context of sustainable transportation. Konidari and Mavrakis (2007) performed AHP, MAUT and the Simple Multi-Attribute Ranking Technique (SMART) for evaluating climate change mitigation policy instruments. Kim et al. (2007) evaluated decommissioning scenarios with MAUT method. Canbolat et al. (2007) performed MAUT method to solve for the global manufacturing facility selection problem. Wang et al. (2010) compared MAUT and Preference Ranking Organization Method for Enrichment Evaluations (PROMETHEE) methods. Briefly the relationships between the thresholds of the preference and the risk attitude of the utility function were discussed. Kailiponi (2010) presented an evacuation process for emergency managers. In this study levels of risk at which point evacuation actions should be taken by emergency managers in a storm surge scenario were identified with MAUT method. Freitas et al. (2013) compared AHP and MAUT methods by applying them to the raw materials selection problem in Brazil. Alp et al. (2015) analyzed the corporate sustainability performance of an international company operating in the chemical industry. In this study entropy method was used for determining the weights of the criteria and MAUT was used for assessment of corporate sustainability performance. Ömürbek et al. (2016) analyzed the performances of automotive companies traded on Istanbul Stock Exchange. The weights of the performance criteria were derived from entropy method and automative companies' performances were ranked with MAUT and SAW methods.

The MAUT approach can be summarised into the following steps:

Step 1: Criteria, sub criteria and alternatives of the decision problem are determined.

Step 2: Criteria weights are computed with one of the weighting methods. In this study criteria weights are derived from CRITIC method.

Step 3: The decision matrix $X$ is formed. It shows the performance of different alternatives with respect to various criteria.

$$
X=\left[x_{i j}\right]_{m \times n}=\left[\begin{array}{cccc}
x_{11} & x_{12} & \cdots & x_{1 n} \\
x_{21} & x_{22} & \cdots & x_{2 n} \\
\vdots & \vdots & \ddots & \vdots \\
x_{m 1} & x_{m 2} & \cdots & x_{m n}
\end{array}\right] \quad(i=1,2 \ldots, m \text { and } j=1,2, \ldots, n)
$$

$x_{i j}$ presents the performance value of $i$ th alternative on $j$ th criterion.

Step 4. The utility function for each criterion is assessed. The value of 1 is assigned to the highest level of satisfaction for a given criterion. On the other hand the value 0 is assigned to the lowest one. Intermediate values may be calculated by the normalization procedure (Freitas et al., 2013). Eq. (6) and Eq. (7) are performed for the beneficial and non-beneficial criteria respectively:

$$
\begin{array}{ll}
u_{j}\left(x_{i j}\right)=\frac{x_{i j}-\min \left(x_{i j}\right)}{\max \left(x_{i j}\right)-\min \left(x_{i j}\right)} & i=1,2, \ldots, m \text { and } j=1,2, \ldots, n \\
u_{j}\left(x_{i j}\right)=\frac{\max \left(x_{i j}\right)-x_{i j}}{\max \left(x_{i j}\right)-\min \left(x_{i j}\right)} & i=1,2, \ldots, m \text { and } j=1,2, \ldots, n
\end{array}
$$

$u_{j}\left(x_{i j}\right)$ is the normalised criteria values determined from single-attribute utility functions on normalised scales.

Step 5. After assessing the utility function for each criterion, the integrated utility of each alternative is computed. Additive utility function shown in Eq. (8) is the simplest model in MAUT. In this model the combined utility of the multiple objectives 
is the sum of the single utility functions multiplied by a scaling constant that reflects the importance of each objective within the decision context (Kailiponi, 2010).

$$
U\left(A_{i}\right)=\sum_{j=1}^{n} w_{j} u_{j}\left(x_{i j}\right)
$$

$U\left(A_{i}\right)$ denotes the utility of alternative $i$; wj denotes the weight of the criterion $j$, and $u_{j}\left(x_{i j}\right)$ denotes is the normalised criteria values determined from single-attribute utility functions on normalised scales. The decision makers should consider the alternative with the highest integrated utility value (Wang et al., 2010).

\section{Application}

In this section, in order to demonstrate the applicability of the CRITIC and MAUT methods, contract manufacturer selection problem of a textile company is considered. This company operates in Denizli and produces towels. The aim of the company is to find the best contract manufacturer which makes their embroidery operations. In this company the staffs from the quality control, production and purchase departments are responsible from searching the alternatives and analyzing them if they suitable or not. Firstly they consider seven criteria affecting their selection decision as material quality $\left(\mathrm{C}_{1}\right)$, on time delivery $\left(C_{2}\right)$, reliability of contract manufacturer $\left(C_{3}\right)$, equipment of contract manufacturer $\left(C_{4}\right)$, geographic location of the contract manufacturer $\left(\mathrm{C}_{5}\right)$, production capacity of the contract manufacturer $\left(\mathrm{C}_{6}\right)$ and cost of the product $\left(\mathrm{C}_{7}, \mathrm{TRY}\right)$. Among these criteria $C_{1}, C_{2}, C_{3}, C_{4}, C_{5}$ and $C_{6}$ are the beneficial criteria where higher values are desirable; $C_{7}$ is non-beneficial criterion where smaller value is always preferred. Considering these criteria the decision committee determines 4 different contract manufacturer alternatives $\left(A_{1}, A_{2}, A_{3}, A_{4}\right)$ around Denizli. The decision committee forms the decision matrix of the contract manufacturer problem based on their knowledge, experience and meetings with the alternatives. The committee uses 5 point scale (5: Excellent, 4: Very good, 3: Good, 2: Fair, 1: Poor) while evaluating the alternatives with respect to first six criteria. Table 1 shows the decision matrix.

Table 1. Decision matrix

\begin{tabular}{llllllll}
\hline & $\mathbf{C}_{1}$ & $\mathrm{C}_{2}$ & $\mathrm{C}_{3}$ & $\mathrm{C}_{4}$ & $\mathrm{C}_{5}$ & $\mathrm{C}_{6}$ & $\mathrm{C}_{7}$ \\
\hline $\mathrm{A}_{1}$ & 3 & 3 & 4 & 3 & 2 & 3 & 2,05 \\
$\mathrm{~A}_{2}$ & 4 & 2 & 2 & 5 & 3 & 2 & 2,15 \\
$\mathrm{~A}_{3}$ & 4 & 3 & 4 & 4 & 1 & 3 & 2,25 \\
$\mathrm{~A}_{4}$ & 3 & 3 & 3 & 3 & 4 & 3 & 2,03 \\
\hline
\end{tabular}

\subsection{Critic Method}

In this section CRITIC method is performed for finding the weights of each criterion. Firstly the decision matrix is normalized by using Eq. (2). The normalized decision matrix is shown in Table 2. The last row of Table 2 shows the values of standard deviations for all criteria. The values of correlation coefficient are then calculated and shown in Table 3 . Finally the criteria weights in Table 4 are determined by using Eq. (3) and Eq. (4).

Table 2. Normalized decision matrix with CRITIC method

\begin{tabular}{llllllll}
\hline & $\mathbf{C}_{1}$ & $\mathbf{C}_{2}$ & $\mathbf{C}_{3}$ & $\mathbf{C}_{4}$ & $\mathbf{C}_{5}$ & $\mathbf{C}_{6}$ & $\mathbf{C}_{7}$ \\
\hline $\mathbf{A}_{1}$ & 0,000 & 1,000 & 1,000 & 0,000 & 0,333 & 1,000 & 0,091 \\
$\mathbf{A}_{2}$ & 1,000 & 0,000 & 0,000 & 1,000 & 0,667 & 0,000 & 0,545 \\
$\mathbf{A}_{3}$ & 1,000 & 1,000 & 1,000 & 0,500 & 0,000 & 1,000 & 1,000 \\
$\mathbf{A}_{4}$ & 0,000 & 1,000 & 0,500 & 0,000 & 1,000 & 1,000 & 0,000 \\
\hline$\sigma_{j}$ & 0,577 & 0,500 & 0,479 & 0,479 & 0,430 & 0,500 & 0,461 \\
\hline
\end{tabular}


Table 3. Correlation coefficient values of the criteria

\begin{tabular}{llllllll}
\hline & $\mathbf{C}_{1}$ & $\mathbf{C}_{2}$ & $\mathbf{C}_{3}$ & $\mathbf{C}_{4}$ & $\mathbf{C}_{5}$ & $\mathbf{C}_{6}$ & $\mathbf{C}_{7}$ \\
\hline $\mathbf{C}_{1}$ & 1 & $-0,577$ & $-0,302$ & 0,905 & $-0,447$ & $-0,577$ & 0,912 \\
$\mathbf{C}_{2}$ & $-0,577$ & 1 & 0,870 & $-0,870$ & $-0,258$ & 1,000 & $-0,197$ \\
$\mathbf{C}_{3}$ & $-0,302$ & 0,870 & 1 & $-0,636$ & $-0,674$ & 0,870 & 0,103 \\
$\mathbf{C}_{4}$ & 0,905 & $-0,870$ & $-0,636$ & 1 & $-0,135$ & $-0,870$ & 0,653 \\
$\mathbf{C}_{5}$ & $-0,447$ & $-0,258$ & $-0,674$ & $-0,135$ & 1 & $-0,258$ & $-0,714$ \\
$\mathbf{C}_{6}$ & $-0,577$ & 1,000 & 0,870 & $-0,870$ & $-0,258$ & 1 & $-0,197$ \\
$\mathbf{C}_{7}$ & 0,912 & $-0,197$ & 0,103 & 0,653 & $-0,714$ & $-0,197$ & 1 \\
\hline
\end{tabular}

Table 4. Criteria weights

\begin{tabular}{llllllll}
\hline Criteria & C1 & C2 & C3 & C4 & C5 & C6 & C7 \\
\hline Cj & 3,514 & 3,016 & 2,761 & 3,329 & 3,652 & 3,016 & 2,506 \\
wj & 0,161 & 0,138 & 0,127 & 0,153 & 0,168 & 0,138 & 0,115 \\
\hline
\end{tabular}

According to Table $4, \mathrm{C}_{5}$ and $\mathrm{C}_{7}$ are the most and least important criteria respectively.

\subsection{Maut Method}

MAUT method is used for finding the rank order of the contract manufacturer alternatives. Firstly, the utility function for each criterion is assessed. Intermediate values are calculated by the normalization procedure. Eq. (6) and Eq. (7) are performed for the beneficial and non-beneficial criteria respectively. The results are presented in Table 5.

Table 5. The utility function for each criterion

\begin{tabular}{llllllll}
\hline & $\mathbf{C}_{1}$ & $\mathbf{C}_{2}$ & $\mathbf{C}_{3}$ & $\mathbf{C}_{4}$ & $\mathbf{C}_{5}$ & $\mathbf{C}_{6}$ & $\mathbf{C}_{7}$ \\
\hline $\mathbf{A}_{1}$ & 0,000 & 1,000 & 1,000 & 0,000 & 0,333 & 1,000 & 0,909 \\
$\mathbf{A}_{2}$ & 1,000 & 0,000 & 0,000 & 1,000 & 0,667 & 0,000 & 0,455 \\
$\mathbf{A}_{3}$ & 1,000 & 1,000 & 1,000 & 0,500 & 0,000 & 1,000 & 0,000 \\
$\mathbf{A}_{4}$ & 0,000 & 1,000 & 0,500 & 0,000 & 1,000 & 1,000 & 1,000 \\
\hline
\end{tabular}

After assessing the utility function for each criterion, the integrated utility of each alternative is computed by Eq. (8). The criteria weights derived from CRITIC method is utilized for these calculations. Finally, the integrated utility of each alternative is shown in Table 6.

Table 6. The integrated utility of each alternative

\begin{tabular}{|c|c|c|c|c|c|c|c|c|}
\hline & $C_{1}$ & $\mathrm{C}_{2}$ & $\mathrm{C}_{3}$ & $\mathrm{C}_{4}$ & $\mathrm{C}_{5}$ & $\mathrm{C}_{6}$ & $C_{7}$ & Total \\
\hline$A_{1}$ & 0,000 & 0,138 & 0,127 & 0,000 & 0,056 & 0,138 & 0,105 & 0,564 \\
\hline$A_{2}$ & 0,161 & 0,000 & 0,000 & 0,153 & 0,112 & 0,000 & 0,052 & 0,478 \\
\hline $\mathbf{A}_{3}$ & 0,161 & 0,138 & 0,127 & 0,076 & 0,000 & 0,138 & 0,000 & 0,641 \\
\hline $\mathrm{A}_{4}$ & 0,000 & 0,138 & 0,063 & 0,000 & 0,168 & 0,138 & 0,115 & 0,623 \\
\hline
\end{tabular}

According to Table 6 , the ranking of contract manufacturer alternatives is $A_{3}-A_{4}-A_{1}-A_{2}$. So $A_{3}$ is decided as the best contract manufacturer for the textile company. 


\section{Conclusion}

In the global competitive environment, companies form strategic alliances with contract manufacturers for utilizing their special expertise and focusing on their core competence (Chen et al., 2005). At this process it is important to work with the right contract manufacturer for gaining competitive advantage. In this paper contracting manufacturer selection problem of a textile company is solved with CRITIC and MAUT methods. CRITIC method is performed for determining the criteria weights whereas ranking of the alternatives is determined by MAUT method. The ranking of the four contract manufacturer alternatives is found as $A_{3}-A_{4}-A_{1}-A_{2}$. According to the ranking order, it is advised to the company to choose the $A_{3}$. The company management found the solving process and results satisfactory. Because both methods do not contain complex and hard computational procedures. So they may be performed for any selection problems by the decision makers easily. For these methods decision matrix is required and there is no boundary in terms of the number of criteria and alternative on this matrix. They allow solving complex decision problems in a consistent manner.

CRITIC method finds objective criteria weights by eliminating decision makers' effect on the decision making process. At the same time CRITIC method does not separate the criteria as beneficial and non-beneficial and it tries to reveal the intensity of the contrast in the structure of the decision making problem. On the other hand MAUT considers the criteria type in the problem and it provides complete preference order of all alternatives. The method may be performed as weighted and un-weighted MAUT.

In future studies, proposed methods may also be applied to other MCDM problems of the company. The number of criteria and alternatives for the contract manufacturer selection problem may be changed. The impacts of any changes in values may be analyzed by sensitivity analysis. The weights of the criteria may be derived from other weighting methods and the ranking of the contract manufacturer alternatives are performed with other MCDM methods. Then final results may be compared.

\section{Acknowledgments}

This paper was financially supported by the Scientific Research Projects Coordination Unit of Pamukkale University.

\section{References}

[1] Alemiardakani, M. (2014). Enhancing Impact Characterization and Multi-Criteria Design Optimization of Glass Fiber Reinforced Polypropylene Laminates (Doctor of Philosophy), The University of British Columbia, Canada.

[2] Alp, I., Öztel, A., \& Köse, M. S. (2015). Entropi tabanli maut yöntemi ile kurumsal sürdürülebilirlik performansı ölçümü: bir vaka çalışması. Ekonomik ve Sosyal Araştırmalar Dergisi, 11 (2), 65-81.

[3] Ananda, J. \& Herath, G. (2005). Evaluating public risk preferences in forest land-use choices using multiattribute utility theory. Ecological Economics, 55(3), 408-419.

[4] Aznar Bellver, J., Cervelló, R.R. \& García, G.F. (2011). Spanish savings banks and their future transformation into private capital banks. determining their value by a multicriteria valuation methodology. European Journal of Economics, Finance and Administrative Sciences, 35, 155-164.

[5] Canbolat, Y. B., Chelst, K. \& Garg, N. (2007). Combining decision tree and MAUT for selecting a country for a global manufacturing facility. Omega, 35(3), 312-325.

[6] Chen, K. S., Chen, K. L. \& Li, R. K. (2005). Contract manufacturer selection by using the process incapability index Cpp. The International Journal of Advanced Manufacturing Technology, 26(5-6), 686692.

[7] Çakır, S. \& Perçin, S. (2013). Çok kriterli karar verme teknikleriyle lojistik firmalarinda performans ölçümü. Ege Akademik Bakış, 13(4), 449-459.

[8] Diakoulaki, D., Mavrotas, G. \& Papayannakis, L. (1995). Determining objective weights in multiple criteria problems: The CRITIC method. Computers Ops Res., 22(7), 763-770.

[9] Freitas, L. V., Freitas, A. P. B. R., Veraszto, E. V., Marins, F. A. S. \& Silva, M. B. (2013). Decision-making with multiple criteria using AHP and MAUT: An industrial application. European International Journal of Science and Technology, 2(9), 93-100.

[10] Gómez-Limón, J. A., Arriaza, M. \& Riesgo, L. (2003). An MCDM analysis of agricultural risk aversion. European Journal of Operational Research, 151(3), 569-585. 
[11] Guo, C., Wang, Y. \& Jiang, W. (2013). An empirical study of evaluation index system and measure method on city's soft power: 17 cities in Shandong province. Cross-Cultural Communication, 9(6), 27-31.

[12] Hu, K. J. \& Yu, V.F. (2016). An integrated approach for the electronic contract manufacturer selection problem. Omega, 62, 68-81.

[13] Iris, L.S. (2014). Evaluation of sustainbility index for urban water management system in Macau. Bachelor of Science Civil Enginering, University of Macau,China.

[14] Işıklar, G., Alptekin, E. \& Büyüközkan, G. (2007). Application of a hybrid intelligent decision support model in logistics outsourcing. Computers \& Operations Research, 34(12), 3701-3714.

[15] Kailiponi, P. (2010). Analyzing evacuation decisions using multi-attribute utility theory. Procedia Engineering, 3, 163-174.

[16] Kazan, H. \& Ozdemir, O. (2014). Financial performance assessment of large scale conglomerates via TOPSIS and CRITIC methods. International Journal of Management and Sustainability, 3(4), 203-224.

[17] Keeney, R.L. \& Raiffa, H. (1976). Decisions with multiple objectives: preferences and value trade offs. John Wiley \& Sons, New York.

[18] Kim, J. \& Yu, K. (2015). Areal feature matching based on similarity using CRITIC method. Joint International Geoinformation Conference, 28-30 October, Kuala Lumpur, Malaysia, 75-78.

[19] Kim, S. K., Park, H. S., Lee, K. W. \& Jung, C. H. (2007). MAUT approach for selecting a proper decommissioning scenario. In Proceedings of the Waste Management Symposium 2007 Conference, Tucson, AZ, USA (Vol. 25).

[20] Konidari, P. \& Mavrakis, D. (2007). A multi-criteria evaluation method for climate change mitigation policy instruments. Energy Policy, 35(12), 6235-6257.

[21] Liu, D. \& Zhao, X. (2013). Method and application for dynamic comprehensive evaluation with subjective and objective information. PLOS ONE, 8(12), 1-5.

[22] Loetscher, T. \& Keller, J. (2002). A decision support system for selecting sanitation systems in developing countries. Socio-Economic Planning Sciences, 36(4), 267-290.

[23] Lu, C., Li, L. \& Wu, D. (2015). Application of combination weighting method to weight calculation in performance evaluation of ICT. 15th International Conference on Advanced Learning Technologies, 258259.

[24] Madic, M. \& Radovanović, M. (2015). Ranking of some most commonly used nontraditional machining processes using ROV and CRITIC methods. U.P.B. Sci. Bull., Series D, 77(2), 193-204.

[25] Milić, M.R. \& Goran, Z.Z. (2012). Objektivni pristup određivanju težına krıterijuma (An objective approach to determining criteria weights). Vojnotehnıčkı glasnık/mılıtary technıcal courıer, 60(1), 39-56.

[26] Mohaghar, A., Kashef, M. O. J. T. A. B. A. \& Khanmohammadi, E. H. S. A. N. (2014). A novel technique to solve the supplier selection problems: combination of decision making trial \& evaluation laboratory, graph theory and matrix approach methods. International Journal of Industrial Engineering, 25(2), 103113.

[27] Nikou, T. (2011). Application of multi-attribute utility theory to heating and cooling system selection for a sustainable building project. (Master Thesis), The Graduate School of Clemson University, USA.

[28] Ömürbek, N., Karaatı, M. \& Balcı, H. F. (2016). Entropi temelli MAUT ve SAW yöntemleri ile otomotiv firmalarının performans değerlemesi. Dokuz Eylül Üniversitesi iktisadi ve Idari Bilimler Fakültesi Dergisi, 31(1), 227-255.

[29] Pohekar, S.D. \& Ramachandran, M. (2004). Application of multi-criteria decision making to sustainable energy planning-A review. Renewable and Sustainable Energy Reviews, 8, 365-381.

[30] Wang, M., Lin, S. J. \& Lo, Y. C. (2010). The comparison between MAUT and PROMETHEE. In Industrial Engineering and Engineering Management (IEEM), 2010 IEEE International Conference on (pp. 753-757). IEEE.

[31] Wang, S., Wee, Y. \& Ofori, G. (2002). DSSDSS: A decision support system for dewatering systems selection. Building and Environment, 37(6), 625-645. 
[32] Y.lmaz, B. \& Harmancıoğlu, N. B. (2010). Multi-criteria decision making for water resource management: a case study of the Gediz River Basin, Turkey. Water SA, 36(5), 563-576.

[33] Zietsman, J., Rilett, L. R. \& Kim, S. J. (2006). Transportation corridor decision-making with multi-attribute utility theory. International Journal of Management and Decision Making, 7(2-3), 254-266. 